\title{
LXXXIX. The discharge of electricity from cylinders and points
}

\section{Professor J.S. Townsend M.A. \& P.J. Edmunds B.A.}

To cite this article: Professor J.S. Townsend M.A. \& P.J. Edmunds B.A. (1914) LXXXIX. The discharge of electricity from cylinders and points, Philosophical Magazine Series 6, 27:161, 789-801, DOI: $10.1080 / 14786440508635151$

To link to this article: http://dx.doi.org/10.1080/14786440508635151

曲 Published online: 08 Apr 2009.

Submit your article to this journal $\lceil\pi$

Џ Article views: 2

Q View related articles $\square$

Citing articles: 5 View citing articles 5 
Discharge of Electricity from Cylinders and Points. $\quad 789$

The real difficulty is not to explain why some unsaturated compounds exist, but why others of analogous chemical constitution are not found in the free state. Thus, for example, it is not so much the existence of $\mathrm{CO}$ that requires explanation as the fact that while in this compound the crrbon atom exerts so little attraction on another carbon atom that the compound $\mathrm{O}=\mathrm{C}=\mathrm{C}=\mathrm{O}$ is not found, in $\mathrm{CH}_{2}$ the carbon atoms have so much affinity for other carbon atoms that $\mathrm{CH}_{2}$ does not under ordinary circumstances exist in a free state (though it is found in vacuum tubes) but at once unites to form the compound $\mathrm{C}_{2} \mathrm{H}_{4}$. Or, to take a case still more analogous, since in $\mathrm{CO}$ the carbon is combined with a more electronegative element, why is not $\mathrm{CCl}_{2}$ found in a free state?

I think we can see a reason for this difference, if we remember that each atom even when saturated produces a strong electric field in its neighbourhood, and that this field will tend to restrict the freedom of motion of the corpuscles in a neighbouring atom. Thus, if the electric field due to the oxygen atom in $\mathrm{CO}$ were very strong, then though only two out of the four mobile corpuscles in the carbon atom are bound by tubes of force to the oxygen atom, the other two would be exposed to a strong electric field and would have their mobility thereby reduced, and in consequence the attraction of the carbon atom on other atoms would be diminished. The diminution in the attraction would depend upon the strength of the electric field in the carbon atom due to the oxygen atom. If the field exerted by the two hydrogen atoms in $\mathrm{CH}_{2}$, or the two chlorine atoms in $\mathrm{CCl}_{2}$, were smaller than that exerted by the oxygen atom in $\mathrm{CO}$, then the carbon atom in $\mathrm{CO}$ would be much more nearly saturated than the ones in $\mathrm{CH}_{2}$ or $\mathrm{CCl}_{2}$, and so the former molecule might exist in a free state while the others could not.

LXXXIX. The Discharge of Electricity from Cylinders and Points. By Professor J. S. Townsend, M.A., New College, Oxford, and P.J. Edmunds, B.A., Queen's College, Oxford*.

1. THE discharge of electricity through gases in those cases where the electric field is not uniform is attended by phenomena which are absent in the case of the uniform fields produced between plane electrodes. The case in which the electrodes are concentric cylinders has been chosen by various investigators as showing these phenomena

* Communierted by the Authors.

Phil. Mag. S. 6. Vol. 27. No. 161. May 1914. 
in a marked degree and also lending itself to mathematical treatment. Some preliminany investigations were made by Baille and Gaugain, but the latest and most complete sets of measurements are those of Watson*, who investigated discharges through air at pressures varying from one atmosphere to half an atmosphere and with wires between 12.8 and $\cdot 7$ millimetres diameter.

It was found t that an explanation of Watson's results could be obtained on the hypothesis that the ionization was due to collision, as had previously been found for discharges between parallel plates at low pressures. The present investigation was undertaken to test the theory over a range of pressures of air from one millimetre to $760 \mathrm{~mm}$. with wires of various diameters.

2. For this purpose two cylinders of brass were used; a large one, internal diameter $14.9 \mathrm{~cm}$. and effective length $66 \mathrm{~cm}$., and a smaller one, internal diameter $3.96 \mathrm{~cm}$. and length $44 \mathrm{~cm}$. These cylinders were fitted with outlet and inlet tubes in the sides for exhausting and admitting air, and the ends were closed by thick glass disks through the centres of which wires of various diameters could be inserted and fixed. The free ends of the wires were enclosed in sealed glass tubes, and the ends connected to the instruments were shielded for some six inches by glass tubes and the

Fig. 1.

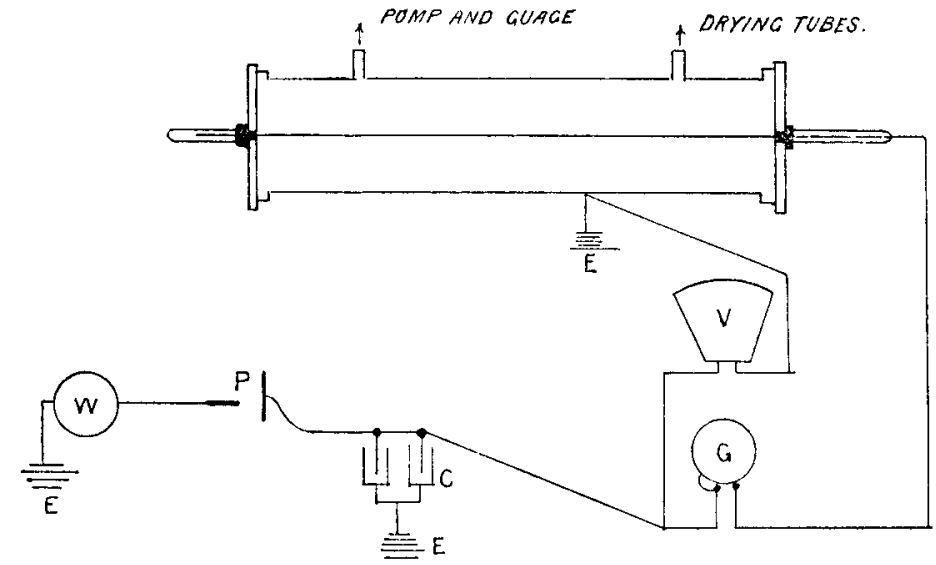

rest by rubber tubing. The arrangement of the apparatus is shown in the accompanying diagram, figure 1.

* E. A. Watson, 'The Electrician,' Feb. 11th, 1910.

† See 'Electrician,' June 6th, 1913. 
Discharge of Electricity from Cylinders and Points. 791

The source of supply was a Wimshurst machine $W$, driven by a small motor, and the insulated system was charged by the discharge from a point, $P$, to a plane. The rate of supply could be regulated by altering the distance between the point and the plane.

The potential was determined by an electrostatic voltmeter, $\mathrm{V}$, connected to the insulated system, and the cylinder, which was permanently connected to earth.

A table galvanometer, $G$, of the moving-coil type, was used to measure the current from the wire to the cylinder. It was sufficiently sensitive to detect a current of about $2 \times 10^{-8}$ ampere per centimetre length of the wire. The galvanometer was insulated from the table by blocks of paraffin wax; one terminal of the coil was connected to the case and to the voltmeter, the other directly to the wire inside the cylinder. Under these conditions the insulation was quite good and the system would remain charged for a considerable period. In many of the experiments leydenjars, C, were connected to the insulated system to nullify irregularities in the supply.

It was, however, found that, in certain cases, more steady currents could be obtained without the extra capacity. This was particularly the case when working with low pressures and the wire negatively charged. In these cases there was a tendency to a "spark discharge" as distinct from the "glow discharge." The effect of the spark discharge was to discharge the system to a potential considerably lower than that at which a discharge commenced, thus rendering the discharge discontinuous. By cutting out the leydenjars the capacity of the system was reduced to a very small quantity, and there was not enough electricity immediately available to supply a current sufficiently large to make a large change in the distribution of electric force. The discharge then became sensibly continuous.

3. The potential necessary to produce the spark was found to be the same as that sufficient to maintain the smallest current detectable with the instruments, and so either was taken as the sparking potential. In all cases except where special mention is made the air used was dried by drawing it slowly through three drying-tubes of about two feet each in length, the first filled with calcium chloride and the other two tightly packed with phosphorus pentoxide. Just before entering the cylinders the air was drawn through a plate of unglazed porcelain to free it from dust.

Irregularities frequently occurred in the negative discharges which have been attributed to dust settling on the $3 \mathrm{G} 2$ 
wire. In these cases the discharge could be seen to take place from one point of the wire and the sparking potential may then be considerably reduced. In order to get consistent results with the glow discharges it is necessary that the glow should cover the wire uniformly.

The general appearance of the discharges was closely similar to that described by Watson. All the inner cylinders, except the largest which was of brass rod, were of copper wire and they were cleaned and polished with metal polish and rouge before use. Wires of five different sizes were used, the largest being $476 \mathrm{~cm}$. in diameter and the smallest $.006 \mathrm{~cm}$. in diameter.

4. On the hypothesis that the sparking potential is determined by ionization by collision a relation can be found between the force $X_{1}$ at the surface of the wire, $a_{1}$ the radius of the wire and $p_{1}$ the pressure of the gas*.

In general, let $\mathrm{V}$ be the potential that produces sparking through a gas at pressure $p$ between any two conductors $A$ and $B$. It may be shown that $V$ is also the sparking potential for two conductors $\mathrm{A}^{\prime}$ and $\mathrm{B}^{\prime}$, obtained from $\mathrm{A}$ and $\mathrm{B}$ by reducing the linear dimensions in the proportion $1 / k$, when the pressure $p^{\prime}$ is $k p$.

Let $\mathrm{P}$ and $\mathrm{Q}$ be two points on a line of force between $A$ and $B, P^{\prime}$ and $Q^{\prime}$ the corresponding points between $A^{\prime}$ and $B^{\prime}$. The number of ions generated by a negative ion in going from $\mathrm{P}$ to $\mathrm{Q}$ is $\alpha d s$ and from $\mathrm{P}^{\prime}$ and $\mathrm{Q}^{\prime}$ is $\alpha^{\prime} l s^{\prime}$.

But

$$
\alpha^{\prime}=p^{\prime} f^{\prime}\left(\frac{\mathrm{X}^{\prime}}{p^{\prime}}\right)=k p f\left(\frac{\mathrm{X}}{p}\right)
$$

and

$$
d s^{\prime}=\frac{1}{k} d s
$$

therefore

$$
\alpha^{\prime} d s^{\prime}=\alpha d s,
$$

similarly for positive ions

$$
\beta d s=\beta^{\prime} d s^{\prime} .
$$

Hence the same effects are produced in corresponding paths in the two cases, so that if the potential $V$ produces a spark in the first case, it will also produce a spark in the second case. Hence the sparking potential $V$ for a pair of cylinders of radii $a$ and $A$ when the pressure is $p$ is the same as that for a pair of cylinders of radii $k a$ and $k \mathrm{~A}$ when the pressure is $p / k$. With the first pair the force $\mathrm{X}_{1}$ at the

\footnotetext{
* Townsend, 'Electrician,' June 6th, 1913.
} 
surface of the inner cylinder is $\mathrm{V} / a \log \mathrm{A} / a$; and with the second pair the force is $\mathrm{V} / k a \log \mathrm{A} / a$.

Hence $a \mathrm{X}_{1}$ is constant when $a p$ is constant for pairs of cylinders which are geometrically similar. Now Gaugain* found that the force at the surface of a given wire, necessary to produce a discharge, was independent of the radius of the outer cylinder. In all his experiments, however, the radius of the outer cylinder was large compared with that of the inner, the pressure being atmospheric, and Baillet found later that if the difference between the radii was small enough the force at the inner surface was affected by the radius of the outer cylinder, the force increasing when this radius was decreased beyond a certain point.

The ionization due to collision ontside the cylindrical surface at which $\mathrm{X} / p=40$ is too small to affect materially the sparking potential, and the condition that the force $X_{1}$ should be independent of the radius of the outer cylinder is that $\mathrm{X}_{0} / p$ should be less than $40, \mathrm{X}_{0}$ being the force at the outer cylinder.

5. In the results used in the following discussion $\mathrm{X}_{0} / p$ was always less than 40 . Hence the theory gives the simple result that $a X_{1}$ should be the same for all wires for the same value of $a p$. To test this a curve, giving the relation between the sparking potential and the pressure, was drawn for each wire; these curves were found to be quite regular and that obtained with a wire 2.38 millimetres radius in a cylinder $7 \cdot 45 \mathrm{~cm}$. radius is shown as an example (fig. 2, p. 799 ). It will be noticed that the curves for negative and positive wires cross at about four millimetres pressure.

Between the pressures $p=3$ and $p=7$ the negative sparking potential changes from 800 volts to 1700 volts. Between these pressures the sparking potential was very irregular.

Similar remarks apply to some of the values obtained from the cylinders II., where the radii were $\cdot 063$ and $1.98 \mathrm{~cm}$. respectively. For this reason some of the figures in the following tables are enclosed in square brackets and are not considered in finding the mean values. This irregularity did not occur with the smaller wires.

The following tables give the values of $a \mathrm{X}_{1}$ corresponding to a series of values of $a p$. The numbers in the different columns are obtained from the sparking potential curves for cylinders of different radii.

* J. M. Gaugain, Ann. de Chin. et de Phys. (4) viii. (1866).

$\dagger$ Baille, Ann. de Chim. et de Phys. (5) xxv. (1882). 
794 Prof. Townsend and Mr. Edmunds on the

$a \mathrm{X}_{1}$ in Volts. Wire positively charged.

\begin{tabular}{|c|c|c|c|c|c|c|c|c|c|}
\hline ap. & $\begin{array}{c}\mathrm{I} \\
\mathrm{A}=7 \cdot 45 \\
a=\cdot 238\end{array}$ & $\begin{array}{c}\text { IT. } \\
A=1.98 \\
a=.063\end{array}$ & $\begin{array}{c}\text { III. } \\
A=7 \cdot 45 \\
a=046\end{array}$ & $\begin{array}{c}\text { IV. } \\
A=1.98 \\
a=0.46\end{array}$ & $\begin{array}{c}\mathrm{V} . \\
\mathrm{A}=1 \cdot 98 \\
a=-0115\end{array}$ & $\begin{array}{c}\text { VI. } \\
A=7 \cdot 45 \\
a=0115\end{array}$ & $\begin{array}{c}\text { VII. } \\
A=1 \cdot 98 \\
a=.003\end{array}$ & $\begin{array}{c}\text { VIII. } \\
\begin{array}{l}\mathrm{A}=7 \cdot 45 \\
a=.003\end{array}\end{array}$ & Mean. \\
\hline $\begin{array}{c}\cdot 05 \\
.1 \\
.25 \\
.5 \\
.7 \\
1 \cdot 0 \\
1 \cdot 5 \\
2 \\
3 \\
4 \\
6 \\
5 \\
10 \\
1 \cdot 2 \\
14 \\
16 \\
18 \\
20\end{array}$ & $\begin{array}{c}\ldots \\
\ldots \\
\ldots \\
\dddot{2} 8 \\
339 \\
407 \\
429 \\
565 \\
675 \\
880 \\
1080 \\
1250 \\
1420 \\
1580 \\
1750 \\
1920 \\
2080\end{array}$ & $\begin{array}{c}\ldots \\
\ldots \\
206 \\
259 \\
288 \\
325 \\
402 \\
494 \\
583 \\
717 \\
930 \\
1120 \\
1320 \\
1500 \\
1680 \\
1860 \\
2010 \\
\ldots\end{array}$ & $\begin{array}{c}\ldots \\
\ldots \\
196 \\
244 \\
277 \\
316 \\
395 \\
472 \\
590 \\
717 \\
914 \\
1110 \\
1310 \\
\ldots \\
\ldots \\
\ldots \\
\ldots \\
\ldots\end{array}$ & $\begin{array}{c}\ldots \\
\ldots \\
189 \\
266 \\
295 \\
346 \\
403 \\
474 \\
606 \\
731 \\
930 \\
1130 \\
1330 \\
\ldots \\
\ldots \\
\ldots \\
\ldots \\
\ldots\end{array}$ & $\begin{array}{c}\ldots \\
\ldots \\
\ldots \\
244 \\
280 \\
329 \\
405 \\
45 \overline{3} \\
611 \\
727 \\
946 \\
1140 \\
\ldots \\
\ldots \\
\ldots \\
\ldots \\
\ldots \\
\ldots\end{array}$ & $\begin{array}{c}145 \\
159 \\
200 \\
253 \\
293 \\
347 \\
432 \\
495 \\
647 \\
774 \\
\ldots \\
\ldots \\
\ldots \\
\ldots \\
\ldots \\
\ldots \\
\ldots\end{array}$ & $\begin{array}{c}\ldots \\
216 \\
270 \\
3019 \\
370 \\
463 \\
540 \\
\ldots \\
\ldots \\
\ldots \\
\cdots \\
\ldots \\
\ldots \\
\ldots \\
\cdots \\
\ldots\end{array}$ & $\begin{array}{c}147 \\
163 \\
201 \\
256 \\
301 \\
365 \\
461 \\
544 \\
\ldots \\
\ldots \\
\ldots \\
\ldots \\
\ldots \\
\ldots \\
\ldots \\
\ldots \\
\ldots\end{array}$ & $\begin{array}{r}146 \\
161 \\
201 \\
256 \\
291 \\
342 \\
421 \\
465 \\
600 \\
723 \\
920 \\
1120 \\
1290 \\
1460 \\
1630 \\
1790 \\
1960 \\
2080\end{array}$ \\
\hline
\end{tabular}

A radius of outer eylinder.

a raclius of inner cylinder.

$a \mathrm{X}_{1}$ in volts. Wire negatively charged.

\begin{tabular}{|c|c|c|c|c|c|c|c|c|c|}
\hline$a_{p}$. & $\begin{array}{c}\text { I. } \\
A=7 \cdot 45 \\
a=\cdot 238\end{array}$ & $\begin{array}{c}\text { II. } \\
A=1.98 \\
a=.063\end{array}$ & $\begin{array}{c}\text { III. } \\
A=7.45 \\
a=046\end{array}$ & $\begin{array}{c}\text { IV, } \\
A=1 \cdot 98 \\
a=\cdot 046\end{array}$ & $\begin{array}{c}\mathrm{V} . \\
A=1.98 \\
a=0.115\end{array}$ & $\begin{array}{c}\text { I. } \\
A=7 \cdot 45 \\
a=0115\end{array}$ & $\begin{array}{c}\text { VII. } \\
A=1.98 \\
a=.003\end{array}$ & $\begin{array}{c}\text { VIII. } \\
A=7.45 \\
a=603\end{array}$ & Mean. \\
\hline $\begin{array}{c}\cdot 05 \\
\cdot 1 \\
\cdot 25 \\
\cdot 5 \\
\cdot 7 \\
1 \cdot 0 \\
1 \cdot 5 \\
2 \\
3 \\
4 \\
6 \\
8 \\
10 \\
12 \\
14 \\
16 \\
18 \\
20\end{array}$ & $\begin{array}{c}\ldots \\
\ldots \\
\ldots \\
\ldots \\
\dddot{.} \\
{[339]} \\
{[466]} \\
552 \\
664 \\
780 \\
998 \\
1200 \\
1400 \\
1590 \\
1760 \\
1950 \\
2110 \\
2240\end{array}$ & $\begin{array}{c}\ldots \\
131 \\
145 \\
189 \\
224 \\
{[253]} \\
{[31]} \\
{[378]} \\
697 \\
831 \\
1070 \\
1280 \\
1480 \\
1670 \\
1860 \\
2040 \\
2240 \\
\ldots\end{array}$ & $\begin{array}{c}\ldots \\
\ldots \\
175 \\
267 \\
321 \\
382 \\
456 \\
560 \\
707 \\
855 \\
1040 \\
1280 \\
1480 \\
\ldots \\
\ldots \\
\ldots \\
\ldots \\
\ldots\end{array}$ & $\begin{array}{c}\ldots \\
\ldots \\
159 \\
189 \\
2 ! 6 \\
348 \\
465 \\
554 \\
700 \\
848 \\
1070 \\
1290 \\
1470 \\
\ldots \\
\ldots \\
\ldots \\
\ldots \\
\ldots\end{array}$ & $\begin{array}{c}\ldots \\
\ldots \\
188 \\
244 \\
294 \\
350 \\
442 \\
524 \\
672 \\
808 \\
1060 \\
1290 \\
\ldots \\
\ldots \\
\ldots \\
\ldots \\
\ldots\end{array}$ & $\begin{array}{l}100 \\
131 \\
177 \\
239 \\
293 \\
363 \\
455 \\
542 \\
646 \\
830 \\
\ldots \\
\ldots \\
\ldots \\
\ldots \\
\ldots \\
\ldots \\
\ldots\end{array}$ & $\begin{array}{l}\ldots \\
\ldots \\
185 \\
262 \\
309 \\
370 \\
463 \\
555 \\
\ldots \\
\ldots \\
\ldots \\
\ldots \\
\ldots \\
\ldots \\
\ldots \\
\ldots \\
\ldots \\
\ldots\end{array}$ & $\begin{array}{c}115 \\
141 \\
193 \\
256 \\
301 \\
365 \\
461 \\
544 \\
\ldots \\
\ldots \\
\ldots \\
\ldots \\
\ldots \\
\ldots \\
\ldots \\
\ldots \\
\ldots\end{array}$ & $\begin{array}{r}107 \\
134 \\
167 \\
234 \\
287 \\
366 \\
457 \\
547 \\
688 \\
835 \\
1050 \\
1270 \\
1460 \\
1630 \\
1810 \\
1990 \\
2170 \\
2940\end{array}$ \\
\hline
\end{tabular}

$A$ radius of outer cylinder $a$ radius of inner cylunder. 
It will be seen that nearly all the results are within five per cent. of the mean in each case. It is remarkable that the results are in such good agreement considering the variaiion which must have been produced by the chemical action of the discharge on the gas. From the mean results curves have been drawn showing the relation between $a \mathrm{X}_{1}$ and $a p$ over the range $a p=\cdot 0.5$ to $a p=20$ (figs. $3 \& 4$ ).

Watson's results may be represented in a similar manner. In his experiments eight different sized wires were used. and it is seen from figure 5 that the points lie very well on a curve, which covers the range from $a p=20$ to $a p=350$.

6 . In the present investigation there was observed in general a marked difference between the sparking potentials when the wire was charged positively and when the wire was charged negatively. For this reason separate curves are given for the values of ap less than 20. At the smaller values of ap the sparking potential was found to be lower when the wire was negative than when it was positive; this is in accordance with Meservey's * results on the discharges from wires in gases at low pressures. But for the larger values of ap investigated, that is to say with ap about 5 to 20 , a lower potential was required to produce a positive discharge. This is contrary - to the generally accepted view ; also, Watson observed no material difference between the two cases; however, most of his measurements were made with much larger values of $a p$.

The theory indicates that there should be some similar phenomenon in the case of the discharge of electricity from blunt points. A large number of measurements have been made by Zeleny $\dagger$ of the sparking potentials of points to planes, the exact shape of the points being defined, as, for example, cylindrical wires with ends rounded approximately to hemispheres. His measurements were nearly all made at atmospheric pressure. With the discharges from the rounded ends of fine wires the sparking potential with the wire negatively charged was lower than with the point positively charged. However, as the size of the wire was increased, this difference decreased regularly, and with a wire $\cdot 05 \mathrm{~cm}$. in diameter the sparking potentials were the same for the two cases. But Zeleny gives no results for negative discharges from points larger than $05 \mathrm{~cm}$. diameter.

7. As this required further investigation the discharges from the ends of wires of diameters $\cdot 05, \cdot 1$, and $\cdot 15$ centimetre were investigated.

* A. B. Meservey, Phil. Mag. [6] xxi p. 479.

t Zelenv, Phys. Rev. xxv. p. 305 (1907). 
The points were made of platinum or silver wire with ends approximately hemispherical, and the planes to which the discharges took place were platinized brass and were fixed at right angles to the axis of the wire. The points and planes were contained under bell-jars fitted with tubes for adjusting the pressure of the air, and measurements of the sparking potentials were made as with the cylinders.

The results showed the same characteristics as those obtained with the cylinders, as may be seen from the following figures :-

\begin{tabular}{|c|c|c|c|}
\hline & $\begin{array}{l}\text { Pressure } \\
\text { in } \mathrm{mm} .\end{array}$ & $\begin{array}{l}\text { Positive } \\
\text { sparking } \\
\text { potential } \\
\text { in volts. }\end{array}$ & $\begin{array}{l}\text { Negative } \\
\text { sparking } \\
\text { potential } \\
\text { in volts. }\end{array}$ \\
\hline $\begin{array}{l}\text { Diameter of wire } 15 \mathrm{~cm} . \\
\text { Distance from plane } 1.5 \mathrm{~cm} . \ldots\end{array}$ & $\begin{array}{r}555 \\
397 \\
220 \\
103 \\
35 \\
13\end{array}$ & $\begin{array}{r}6200 \\
5080 \\
3450 \\
2200 \\
1320 \\
975\end{array}$ & $\begin{array}{r}7000 \\
5500 \\
3800 \\
2450 \\
1280 \\
825\end{array}$ \\
\hline $\begin{array}{l}\text { Diameter of wire } 10 \mathrm{~cm} . \ldots . . \\
\text { Distance from plane } 10 \mathrm{~cm} . \ldots\end{array}$ & $\begin{array}{r}763 \\
213 \\
81\end{array}$ & $\begin{array}{l}6400 \\
2950 \\
1700\end{array}$ & $\begin{array}{l}6800 \\
3130 \\
1700\end{array}$ \\
\hline $\begin{array}{l}\text { Diameter of wire } 0.5 \mathrm{~cm} . \ldots \ldots \\
\text { Distance from plane } 1.5 \mathrm{~cm} . \ldots\end{array}$ & $\begin{array}{l}760 \\
265\end{array}$ & $\begin{array}{l}5300 \\
2900\end{array}$ & $\begin{array}{l}5300 \\
2700\end{array}$ \\
\hline
\end{tabular}

8. It is interesting to see whether this result can be explained on the hypothesis that the effect is due to ionization by collision.

The relation* which must hold between the values of $\alpha$ and $\beta$ along a radius $r$ between two cylinders, radii $a$ and $A$, before a continuous discharge can take place is

$$
I=\int_{a}^{A} \alpha e^{-\int_{a}^{r}(\alpha-\beta) d r} d r
$$

when the inner cylinder is negatively charged.

The corresponding condition for the case in which the inner cylinder is positively charged is obtained by interchanging $\alpha$ and $\beta$ in the above integral, and it does not follow that a system of values of $\alpha$ and $\beta$ which satisfies the first also satisfies the second. Hence the system of forces required for a positive discharge is in general different from the system required to maintain a negative discharge.

* 'Ionization of Gases by Collision,' p. 66. 
The effect of concentrating the force near an electrode may be seen by considering the case in which the system of forces between two conductors is slightly less than that which is required to produce a discharge. If the integral

$$
\int_{0}^{l} \alpha e^{-\int_{0}(\alpha-\beta) d s} d s
$$

along the path of the discharge is slightly less than unity, it may be brought up to the required value by increasing the force for a short distance $d s$ either at the positive or at the negative electrode.

If $\alpha$ and $\beta$ be increased to $\alpha+\delta \alpha_{1}$ and $\beta+\delta \beta_{1}$ from $s=0$ to $s=\delta s$ then the increase in the integral is $\delta \beta_{1} \delta s$. If $\alpha$ and $\beta$ be increased to $\alpha+\delta \alpha_{2}$, and $\beta+\delta \beta_{2}$ from $s=l-\delta s$ to $s=l$. the increase in the integral is

$$
\delta s \delta \alpha_{2} e^{-\int_{0}^{l}(\omega-\beta) d s} .
$$

Hence, it is more advantageous to increase the force at the negative electrode than at the positive if

$$
\frac{d \beta_{1}}{d \mathrm{X}} \text { exceeds } \frac{d \alpha_{2}}{d \mathrm{X}} e^{-\int_{0}^{l}(\alpha-\beta) d s} \text {. }
$$

For the case of a uniform field the condition for sparking is

$$
\beta=\alpha e^{-(\alpha-\beta) l} \text {. }
$$

Hence, if the uniform force is not great enough to produce a discharge, it is more advantageous to increase the furce at the negative electrode than at the positive electrode if

$$
\frac{1}{\beta} \frac{d \beta}{d \mathrm{X}}>\frac{1}{\alpha} \frac{d \alpha}{d \bar{X}}
$$

The determinations of $\alpha / p$ and $\beta / p$ that have been made for the larger values of $\mathrm{X} \mid p$, from $\mathrm{X} / p=150$ to 500 , show that over this range the quantity $\frac{1}{\beta} \frac{d \beta}{d \mathrm{X}}$ is greater than $\frac{1}{\alpha} \frac{d \alpha}{d \mathrm{X}}$ and the discharges are generally obtained more easily when the force is concentrated at the negative electrode. The sparking potentials are comparatively small in these cases, but as $\mathrm{X} / p$ diminishes the sparking potentials increase and the effect of concentrating the force at the negative electrode may be quite different.

It would, however, be impossible to find from theoretical 
considerations the difference between the sparking potentials for positive and negative discharges when the potentials are large, as the values of $\beta / p$ corresponding to the smaller values of $\mathrm{X} / p$, from $\mathrm{X} / p=40$ to 150 , have not yet been determined accurately.

The fact that the positive discharges are produced by smaller potentials than the negative discharges in these cases is not contrary to the theory, since it is quite possible that $\frac{1}{\beta} \frac{d \beta}{d \mathrm{X}}$ may become small in comparison with $\frac{1}{\alpha} \frac{d \alpha}{d \mathrm{X}}$ when $\mathrm{X} / p$ is between the limits 40 to 150 .

The above investigations apply to cases in which the ions are generated in a space near the inner cylinder, and the force $X_{0}$ at the surface of the outer cylinder is less than $40 \times p$.

9. The effect on the sparking potential when the outer cylinder is so small that $\frac{\mathrm{X}_{0}}{\mu^{\prime}}$ is greater than 40 is shown by a measurement of the sparking potential abtained with a pressure of 1.35 millimetre between cylinders of radii $.063 \mathrm{~cm}$. and $1.98 \mathrm{~cm}$. When the wire was positively charged the sparking potential was found to be 640 volts. This gives $\frac{\mathrm{X}_{0}}{p}=69$. Hence it is to be expected that the value of $a \mathrm{X}_{1}$ should be higher than that obtained in other cases where $\frac{X_{0}}{p}$ is less than 40 ; for the outer cylinder cuts off part of the region where the force is large enough to produce a considerable amount of ionization. The value of $a \mathrm{X}_{1}$ obtained from the above result is 186 , which is, in fact, considerably higher than the value 150 taken from the curve for the same value, 0.85 , of $a / p$. On the other hand, the negative sparking potential for the same cylinders and air-pressure was found to be 420 volts, giving $a \mathrm{X}_{1}=122$, which agrees with the value 118 taken from the curve. This is quite consistent since the value of $\mathrm{X}_{0} / p$ is only 45 .

10. Some observations were also made of the relation of the rise in potential to the current and also of the effect of moisture. It was found impossible to work with very damp air withont completely reconstructing the apparatus as the moisture settled on the surfaces of the insulators. However, some experiments were made with air taken from the room and freed from dust without being dried. This amount of moisture had no appreciable effect on the sparking potentials, but the increase of potential required to maintain 
Discharge of Electricity from Cylinders and Points. 799

Fig. 2.

Sparking Potentials.

Radius of inner cylinder $238 \mathrm{~cm}$.

" outer cylinder $7.45 \mathrm{~cm}$.

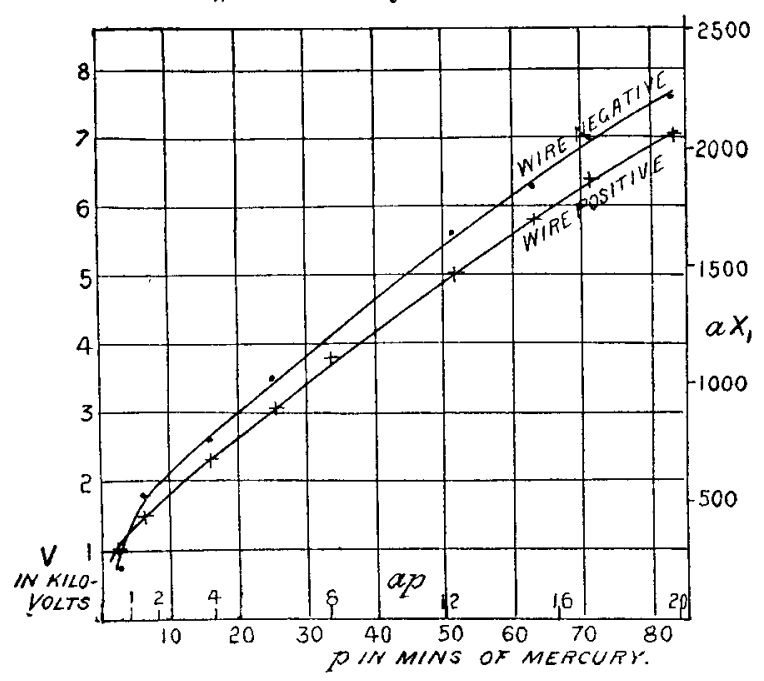

Fig. 3.

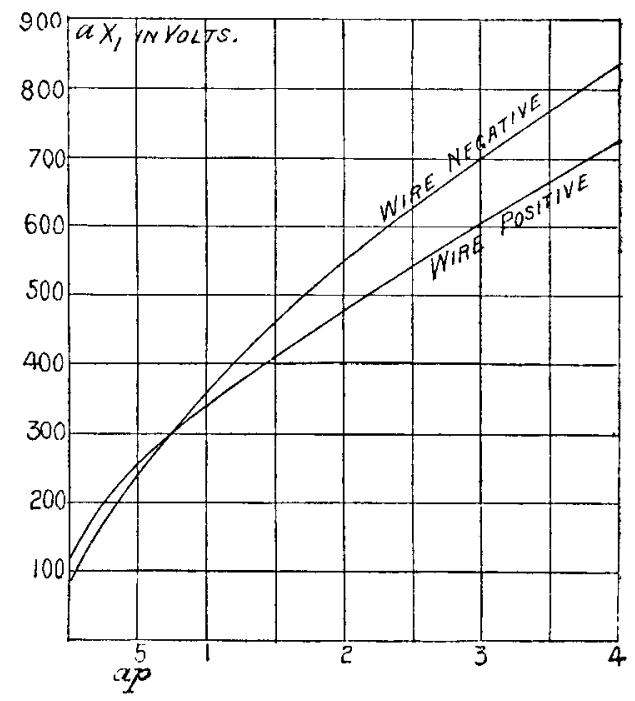


800 Discharge of Electricity from Cylinders and Points.

Fig. 4.

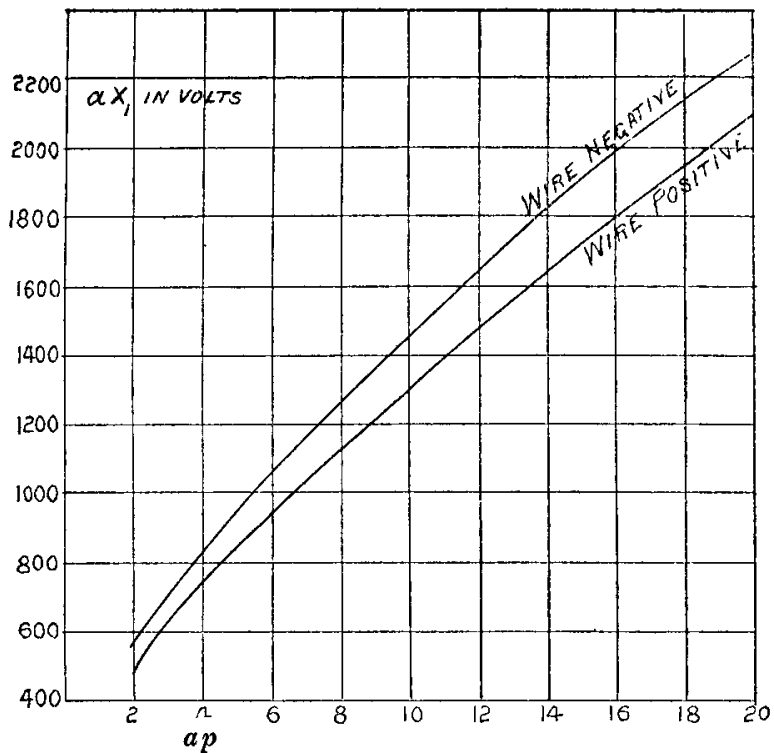

Fig. 5.

Results taken from paper by E. A. Watson, 'Electrician,' Feb. 11th, 1910.

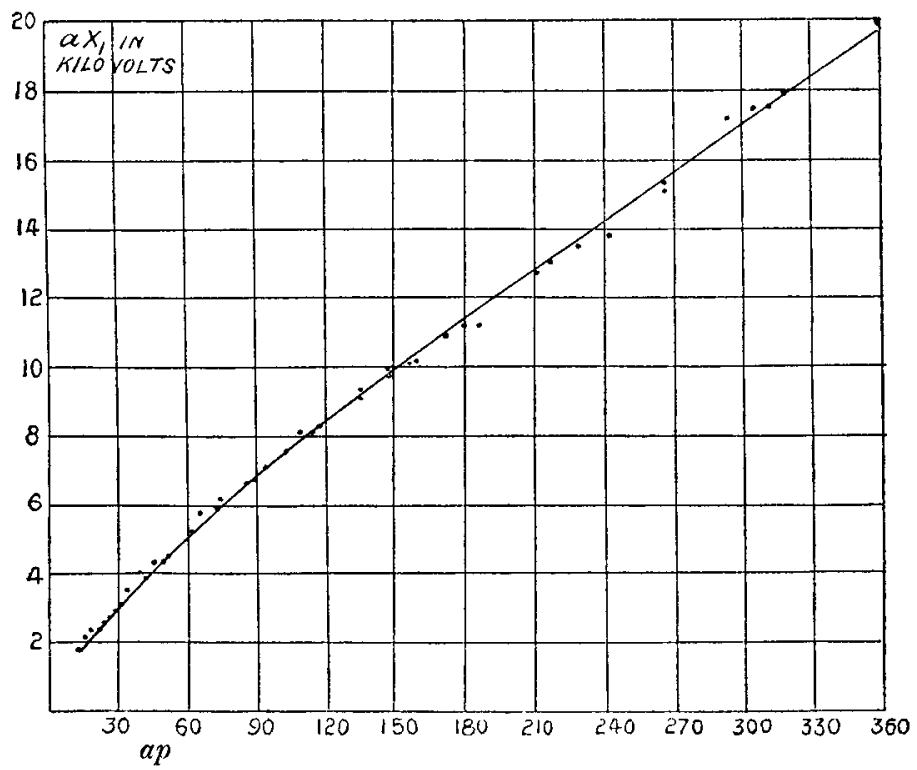


a given negative discharge depended on the dryness of the air. The theory shows that the potential $v$ required to maintain a small current $I$ is given by the formula

$$
v(v-\mathrm{V})=\frac{\mathrm{IA}^{2} \log \mathrm{A} / a}{2 k},
$$

$k$ being the velocity of the ions under unit electric force and $\mathrm{V}$ the sparking potential. The potentials $v$ required to maintain small currents were quite consistent with this expression, but no very accurate determinations of $k$ have yet been deduced from the observations.

It was found that $d \mathrm{I} / d v$ was smaller for positive discharges than for negative discharges. Also when the air was damp, $d \mathrm{I} / d v$ for negative discharges diminished, showing that the negative ions, in the space in which $\alpha / p$ is small, are affected by the moisture. But in the space near the inner cylinder where $\mathrm{X} / p$ is large the negative ions are not affected by the moisture since the sparking potentials are the same for moist and dry gases.

XC. The Spectroscopy of the Electric Brush Discharge in Weak Acids and Solutions. By Harolo Smith, M.Se. (1851 Exhititioner)*.

\author{
[Plate XI.] \\ Introduction.
}

THE changes which occur in the spectra of the electric 1 brush discharge in solutions under varying electrical conditions have already been investigated in a previous paper $\dagger$. In the experiments there considered the brush was produced by means of a large induction-coil, the primary of which was fed with alternating current. The secondary terminals were connected to two electrodes immersed in a small cell containing water or some dilute solution. One of these electrodes was an inch square of platinum foil ; the other was a platinum wire fused into a glass tube, with the protruding end of the wire filed till it was flush with the glass. A luminous brush occurred at the end thus exposed. $\AA$ condenser was arranged in parallel with the cell and an adjustable spark-gap in series with it when a condensed brush was requiired. Striking variations in the spectra were found according to the nature of the solution, its concentration, and the type of discharge used. Other variations occur when

* Communicated by Prof. Sir J. J. Thomson, O.M., F.R.S.

† Phil Mag. [6] vol. xxv. p. 461 (1913). 